Quim. Nova, Vol. 33, No. 3, 618-623, 2010

\title{
EMISSÃO DE ÓXIDO NITROSO DE ESTAÇÃO DE TRATAMENTO DE ESGOTO DE LODOS ATIVADOS POR AERAÇÃO PROLONGADA - ESTUDO PRELIMINAR
}

\author{
Ariane Coelho Brotto, Débora Cynamon Kligerman e Andrezza de Souza Piccoli \\ Departamento de Saneamento e Saúde Ambiental, Escola Nacional de Saúde Pública, Fundação Oswaldo Cruz, Rua Leopoldo \\ Bulhões, 1480, 21041-210 Rio de Janeiro - RJ, Brasil \\ William Zamboni de Mello* \\ Departamento de Geoquímica, Instituto de Química, Universidade Federal Fluminense, Outeiro de São João Batista, s/n, \\ 24020-141 Niterói - RJ, Brasil
}

Recebido em 27/4/09; aceito em 2/10/09; publicado na web em 10/3/10

\begin{abstract}
NITROUS OXIDE EMISSIONS FROM AN ACTIVATED SLUDGE WASTEWATER TREATMENT PLANT WITH PROLONGED AERATION PROCESS - A PRELIMINARY STUDY. Nitrous oxide emissions from an activated sludge plant which serves a research institute in Rio de Janeiro city were estimated from six unit processes (grit tank, sand trap, aeration tank, secondary settling tank, sludge recirculation line and aerobic digester sludge tank) and also from the plant effluent. Total estimated annual flux was $3.2 \times 10^{4}$ $\mathrm{g} \mathrm{N}_{2} \mathrm{O} \mathrm{yr}^{-1}$ of which about $90 \%$ was from the aeration tank. Emission factors estimated from population served, wastewater flow and nitrogen load (conversion ratio) were $13 \mathrm{~g} \mathrm{~N}_{2} \mathrm{O}$ person $^{-1} \mathrm{yr}^{-1}, 9.0 \times 10^{-5} \mathrm{~g} \mathrm{~N}_{2} \mathrm{O} \mathrm{L}_{\text {wastewater }}{ }^{-1}$ and $0.14 \%$.
\end{abstract}

Keywords: nitrous oxide; wastewater treatment; activated sludge.

\section{INTRODUÇÃO}

Várias ações humanas podem contribuir para mudanças climáticas devido a alterações nas concentrações de alguns gases e partículas na atmosfera. Gases do efeito estufa (GEEs) e partículas em suspensão no ar podem influenciar no balanço de energia da Terra, i.e., afetando a dissipação de radiação infravermelha emitida pelo planeta e a incidência de radiação solar. ${ }^{1}$ Dentre os três principais GEEs, dióxido de carbono $\left(\mathrm{CO}_{2}\right)$, metano $\left(\mathrm{CH}_{4}\right)$ e óxido nitroso $\left(\mathrm{N}_{2} \mathrm{O}\right)$, o último é o menos abundante na atmosfera, mas, por outro lado, é aquele que possui maior potencial de aquecimento global, sendo, por molécula, 300 vezes superior ao do $\mathrm{CO}_{2}$. Além disso, $\mathrm{o} \mathrm{N}_{2} \mathrm{O}$ contribui indiretamente para o consumo do ozônio $\left(\mathrm{O}_{3}\right)$ estratosférico $\left[\mathrm{N}_{2} \mathrm{O}+\mathrm{O}\left({ }^{1} \mathrm{D}\right) \rightarrow\right.$ $2 \mathrm{NO} ; \mathrm{NO}+\mathrm{O}_{3} \rightarrow \mathrm{NO}_{2}+\mathrm{O}_{2}$ ], gás que protege a superfície do planeta de uma maior incidência de radiação ultravioleta. ${ }^{1,2}$ Sua concentração atual é de $320 \mathrm{ppb}$ (parte por bilhão), apresentando um crescimento linear nas duas últimas décadas de aproximadamente $0,3 \%$ ano $^{-1} \cdot{ }^{1} \mathrm{O}$ aumento total nos dois últimos séculos foi de $50 \mathrm{ppb}$ ou de $18,5 \%$ em relação a sua concentração no período pré-industrial, quando se encontrava em $270 \mathrm{ppb}^{2}$

Atividades microbiológicas na superfície dos solos e oceanos representam a principal fonte natural global de $\mathrm{N}_{2} \mathrm{O} .{ }^{2}$ Entre as atividades antrópicas, o uso de fertilizantes nitrogenados na agricultura, a criação de animais para produção de alimentos, o desmatamento e a queima de biomassa têm sido apontadas como as principais fontes, embora as incertezas associadas às estimativas das taxas de emissão dessas fontes sejam altas. ${ }^{1-3}$ Poucos são os estudos sobre emissões de $\mathrm{N}_{2} \mathrm{O}$ realizados diretamente em sistemas de tratamento de esgoto com lodo ativado e os resultados entre os diferentes trabalhos mostram grandes discrepâncias. ${ }^{4}$ As Diretrizes de 2006 do Painel Intergovernamental sobre Mudanças Climáticas (Intergovernmental Panel on Climate Changes, IPCC) para Inventários Nacionais de Gases do Efeito Estufa propõem como fator de emissão 3,2 (2-8) g $\mathrm{N}_{2} \mathrm{O}$ pessoa $^{-1}$ ano $^{-1}$ para o caso de estações de tratamento de esgoto (ETEs) com processos de nitrificação e desnitrificação controlados. ${ }^{5}$

*e-mail: zamboni@geoq.uff.br
Esse fator de emissão provém do estudo realizado por Czepiel et al., ${ }^{6}$ que mediram as emissões de $\mathrm{N}_{2} \mathrm{O}$ de uma ETE municipal na cidade de Durham, localizada em região de clima temperado, no nordeste dos Estados Unidos. Em virtude da ausência de informações relativas a emissões de $\mathrm{N}_{2} \mathrm{O}$ em ETEs localizadas em países de clima tropical, em 2007 deu-se início a um estudo que teve como objetivo medir fluxos de $\mathrm{N}_{2} \mathrm{O}$ em diferentes unidades do processo de tratamento e linhas de transferência de esgoto e lodo de uma ETE de lodos ativados por aeração prolongada localizada em um instituição de pesquisa na cidade do Rio de Janeiro.

\section{PARTE EXPERIMENTAL}

\section{Local de estudo}

A ETE estudada localiza-se em uma instituição de pesquisa na área de saúde pública na cidade do Rio de Janeiro. A ETE dessa instituição tem funcionamento contínuo e atende a aproximadamente 2.500 usuários. O esgoto destinado à ETE possui predominantemente $(\sim 70 \%)$ características de esgoto domiciliar. Uma menor contribuição provém de esgotos de laboratórios de pesquisa na área de farmacoquímica e microbiologia, em geral.

\section{Características principais do processo de tratamento de esgoto de lodos ativados}

O sistema estudado é o de lodos ativados por aeração prolongada, processo de tratamento de esgotos mais eficiente no que tange à demanda bioquímica de oxigênio (DBO). ${ }^{7}$ Nesse tipo de tratamento, a biomassa permanece no sistema por um período maior devido à recirculação do lodo, sendo assim o tanque de aeração (reator biológico) possui maior volume e quantidade de biomassa. As seguintes unidades são partes integrantes do sistema de lodos ativados por aeração prolongada utilizado (Figura 1): tratamento preliminar com gradeamento, desarenador (caixa de areia), tanque de aeração (reator biológico), decantador secundário (tipo Dortmund com três câmaras), linha de recirculação e digestor aeróbio de lodo. Sequencialmente, 
o esgoto bruto passa pela grade, onde são removidos os sólidos grosseiros. Deste ponto é bombeado para uma calha por onde escoa até atingir o desarenador, onde os sólidos restantes se decantam e o afluente é lançado no tanque de aeração. Este possui duas regiões, uma anóxica, onde ocorre o lançamento do esgoto bruto, e outra aeróbia. O esgoto circula da região anóxica para a região aeróbia. A aeração é feita por meio de difusores. Do tanque de aeração o lodo segue para o decantador secundário. O líquido sobrenadante do decantador secundário é transferido por gravidade a uma calha, seguindo para o corpo receptor e o lodo assentado nas câmaras é recirculado, por cerca de 25 dias, para o tanque de aeração. Quando o lodo se encontra estabilizado, i.e., quando a análise de sólidos sedimentáveis atinge aproximadamente $250 \mathrm{~mL} \mathrm{~L}^{-1}$, é transferido para o digestor de lodo, onde é aerado antes de ser descartado para os leitos de secagem. Esse descarte é feito em média uma vez a cada 3 semanas.

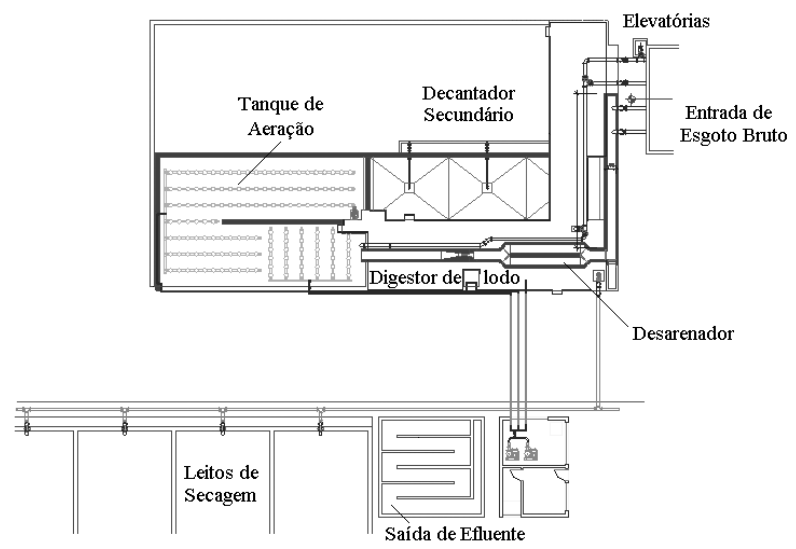

Figura 1. Adaptação da planta baixa da estação de tratamento de esgoto de lodos ativados por aeração prolongada estudado. Fonte: memorial descritivo do projeto

A injeção de ar no tanque de aeração e no digestor de lodo é feita por meio de 195 difusores de ar, dos quais 141 se encontram distribuídos no tanque de aeração e 54 no digestor de lodo. Dos 141 difusores do tanque de aeração, 36 situam-se na região anóxica do tanque e encontram-se permanentemente fechados, e os demais (105) na região aeróbia. De acordo com a distribuição dos difusores, a região anóxica compreende aproximadamente $25 \%$ do total do tanque de aeração. A vazão total de injeção de ar em todo o sistema de aeração é de $700 \mathrm{~m}^{3} \mathrm{~h}^{-1}$ que são efetivamente distribuídos entre os 105 difusores do tanque de aeração e os 54 do digestor de lodo. Dessa forma, considera-se que as vazões de entrada de ar no tanque de aeração e no digestor de lodo sejam, respectivamente, 460 e $240 \mathrm{~m}^{3} \mathrm{~h}^{-1}$. Não há medidores de vazão na ETE de forma que se possa conhecer a vazão de entrada de ar efetiva nessas unidades; por essa razão esses mesmos valores serão utilizados posteriormente para as estimativas dos fluxos de $\mathrm{N}_{2} \mathrm{O}$ (do lodo para a atmosfera) dessas unidades.

$\mathrm{O}$ efluente da ETE apresenta $\mathrm{DBO}_{5}$, a $20{ }^{\circ} \mathrm{C}$, média de aproximadamente $200 \mathrm{mg} \mathrm{L}^{-1}$, apresentando uma eficiência de remoção da DBO de $95 \%$. A concentração de nitrogênio total no esgoto é em média $40 \mathrm{mg} \mathrm{N} \mathrm{L}{ }^{-1}$.

\section{Coletas e tratamento de amostras}

A coleta de amostras ocorreu no período de outubro de 2007 a dezembro de 2008, compreendendo um total de 15 campanhas realizadas em 6 unidades da ETE, sendo elas: entrada de esgoto bruto (grade), desarenador, tanque de aeração, decantador secundário, recirculação do lodo e digestor de lodo. Além dessas unidades, foram efetuadas medidas na saída do efluente. Não se efetuaram medidas de fluxos de $\mathrm{N}_{2} \mathrm{O}$ nos leitos de secagem, unidade da ETE para onde é transferido o lodo após uma permanência de aproximadamente 3 semanas no digestor de lodo. Esse estudo será realizado em trabalho posterior. A seguir são descritos os procedimentos adotados para coleta de amostras líquidas [esgoto bruto (afluente) e esgoto tratado (efluente)] e de ar para as determinações das concentrações de $\mathrm{N}_{2} \mathrm{O}$ nesses meios, para posterior cálculo das taxas de emissão de $\mathrm{N}_{2} \mathrm{O}$. Todas as coletas de amostras na ETE foram efetuadas no período entre 8:30 e 12:00 h, e todas as determinações de $\mathrm{N}_{2} \mathrm{O}$ foram efetuadas no mesmo dia das coletas.

Para estimativa das taxas de emissão de $\mathrm{N}_{2} \mathrm{O}$ das diversas unidades da ETE utilizaram-se 3 técnicas: 1) câmara estática, para determinação direta dos fluxos de $\mathrm{N}_{2} \mathrm{O}$ na interface líquido-atmosfera, adotada em uma unidade sem turbulência do meio líquido, como no caso do decantador secundário; 2) funil emborcado, para determinação da concentração de $\mathrm{N}_{2} \mathrm{O}$ nas bolhas de ar emanadas da superfície do esgoto nos sistemas aerados (i.e., onde há injeção de ar atmosférico), como nos casos do tanque de aeração e do digestor de lodo e, 3) balanço de massa, para determinação da perda de $\mathrm{N}_{2} \mathrm{O}$ do meio líquido para a atmosfera por difusão ou turbulência em trechos em que há transferência de líquidos, como no caso da recirculação do lodo, bem como nos trechos entre a entrada do esgoto bruto e o tanque de aeração, e entre o decantador secundário e a saída do efluente da ETE. Essas técnicas estão descritas detalhadamente a seguir.

\section{Câmara estática}

No decantador secundário, os fluxos de $\mathrm{N}_{2} \mathrm{O}$ na interface líquido atmosfera foram medidos utilizando-se a técnica da câmara estática. ${ }^{8-10}$ Este método consiste no uso de uma câmara de PVC (policloreto de vinila) em formato cilíndrico (diâmetro $=25 \mathrm{~cm}$; altura $=20 \mathrm{~cm}$ ), que é ajustada uma placa de isopor de 3,0 cm de espessura, para que permita sua flutuação (Figura 2). Uma vez assentada a câmara à superfície do líquido, 4 amostras de ar ( 20 mL) são coletadas de seu interior em intervalos de tempo iguais. Esse tempo foi, em geral, de 5 min. Imediatamente após o assentamento da câmara é coletada uma amostra de ar atmosférico (externo à câmara). Essas amostras são coletadas por meio de seringas de polipropileno de $20 \mathrm{~mL}$ (Becton Dickinson). Com os resultados das concentrações de $\mathrm{N}_{2} \mathrm{O}$ dessas 5 amostras, é calculado o fluxo (F) de $\mathrm{N}_{2} \mathrm{O}$ através da Equação 1:

$\mathrm{F}=\mathrm{h} \times \mathrm{dC} /\left.\mathrm{dt}\right|_{\mathrm{t}=0}$,

onde h representa a altura entre a superfície do líquido e o topo da câmara $(\sim 15 \mathrm{~cm})$ e dC/dt $\left.\right|_{t=0}$ a variação da concentração de $\mathrm{N}_{2} \mathrm{O}$ no interior da câmara, a partir da concentração atmosférica inicial, em função do tempo.

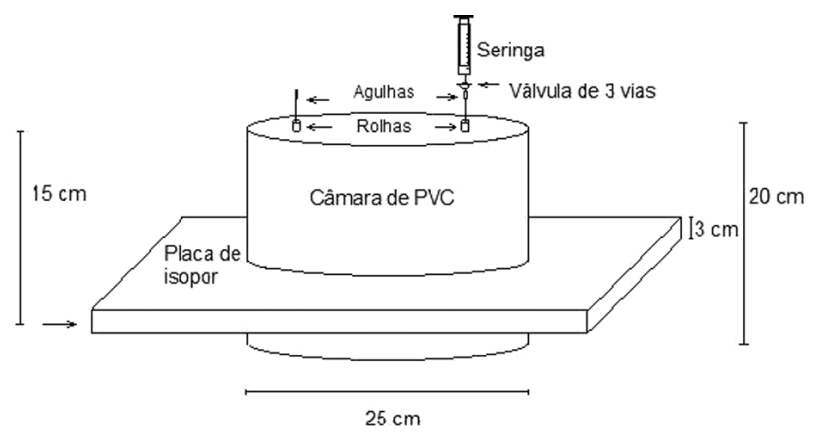

Figura 2. Câmara estática, com flutuador, utilizada para medidas de fluxo de $\mathrm{N}_{2} \mathrm{O}$ na interface líquido-atmosfera no decantador secundário da ETE. A seta horizontal à esquerda indica aproximadamente o nível do líquido após assentamento da câmara à superfície do líquido 


\section{Funil emborcado}

No tanque de aeração e no digestor de lodo, unidades da ETE onde há injeção de ar por difusores, para aeração do esgoto e do lodo, foi utilizada uma técnica que permite a captação das bolhas de ar que se desprendem da superfície do esgoto aerado, cuja finalidade é a determinação da concentração de $\mathrm{N}_{2} \mathrm{O}$ no ar desprendido do esgoto para posterior cálculo da taxa de emissão do $\mathrm{N}_{2} \mathrm{O}$ dessas unidades da ETE. Essa técnica consiste no uso de um funil de polietileno de $30 \mathrm{~cm}$ de diâmetro (área $=0,071 \mathrm{~m}^{2}$ ) a cujo gargalo foi externamente inserido um tubo de PVC (comprimento $~ 2 \mathrm{~m}$; diâmetro $=5 \mathrm{~cm}$ ) (Figura 3). Para isso, a extremidade do tubo de PVC inserida ao gargalo do funil foi previamente aquecida para torná-lo flexível no amoldamento ao gargalo do funil. A parte superior do tubo de PVC é aberta, permitindo a saída do ar resultante do rompimento das bolhas emanadas da superfície do esgoto. Por dentro do tubo de PVC fixou-se um tubo plástico flexível com diâmetro interno de $4 \mathrm{~mm}$, que se estende do meio do gargalo do funil até a outra extremidade do tubo de PVC, através do qual é retirada a amostra por meio de uma seringa de polipropileno de $20 \mathrm{~mL}$. Para coleta de amostras do ar resultante do rompimento das bolhas na superfície do esgoto, imerge-se o funil até que o nível do líquido atinja aproximadamente $2 / 3$ da altura total acima da boca do funil (em posição emborcada), conforme mostrado na Figura 3.

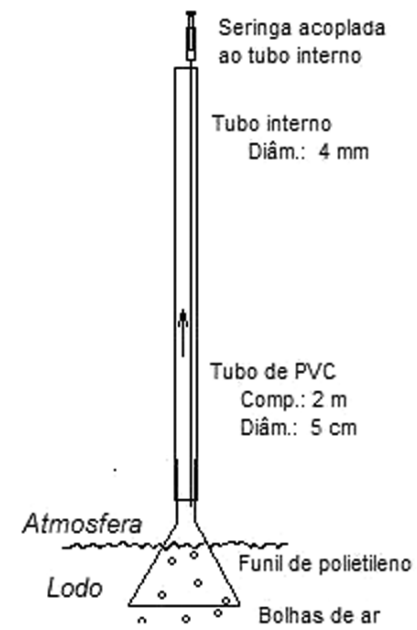

Figura 3. Funil emborcado para determinação da concentração de $\mathrm{N}_{2} \mathrm{O}$ nas bolhas de ar emanadas da superfície do esgoto da ETE - técnica utilizada no tanque de aeração e no digestor de lodo. A seta vertical indica a direção do deslocamento do ar, resultante do rompimento das bolhas de ar exaladas da superfície do esgoto, no interior do tubo de PVC. A amostra é retirada de um local próximo ao gargalo do funil, por meio de seringa, através do tubo flexível de $4 \mathrm{~mm}$

A taxa de emissão (TE) de $\mathrm{N}_{2} \mathrm{O}$ da superfície do esgoto, expressa em unidade de massa de $\mathrm{N}_{2} \mathrm{O}$ por tempo, é calculada através do produto da vazão total de ar injetado $(\mathrm{Q})$ no tanque de aeração (ou no digestor de lodo) pela diferença entre a concentração de $\mathrm{N}_{2} \mathrm{O}$ nas bolhas que afloram na superfície do esgoto e a concentração atmosférica, $\Delta\left[\mathrm{N}_{2} \mathrm{O}\right]$. Assim, tem-se:

$\mathrm{TE}=\mathrm{Q} \times \Delta\left[\mathrm{N}_{2} \mathrm{O}\right]$

$\Delta\left[\mathrm{N}_{2} \mathrm{O}\right]=\left[\mathrm{N}_{2} \mathrm{O}\right]_{\text {bolhas }}-\left[\mathrm{N}_{2} \mathrm{O}\right]_{\mathrm{ar}}$

O volume de ar interno (headspace) do funil emborcado, considerando-se da superfície do esgoto até a ponta inferior do tubo plástico flexível, através do qual a amostra é aspirada pela seringa, é de aproximadamente 3,0 L (com base nas dimensões do dispositivo utilizado). O tanque de aeração da ETE possui uma área de $110 \mathrm{~m}^{2}$ da qual aproximadamente $25 \%$ é constituída pela região anóxica. Com base na área da região aeróbia do tanque de aeração $\left(\sim 83 \mathrm{~m}^{2}\right)$, na vazão de injeção de ar nesse setor do tanque (vazão de projeto $=460 \mathrm{~m}^{3} \mathrm{~h}^{-1}$ ) e na área de captação de bolhas do funil $\left(0,071 \mathrm{~m}^{2}\right)$, estima-se que a vazão de entrada de ar no funil utilizado para captação de bolhas seja de aproximadamente $6,6 \mathrm{~L} \mathrm{m^{-1 }}$. No caso do digestor de lodo (área $=40 \mathrm{~m}^{2}$; vazão de projeto $=240 \mathrm{~m}^{3} \mathrm{~h}^{-1}$ ), a vazão de captação de bolhas pelo funil é estimada em 7,1 L min-1. Após imersão parcial do funil para coleta da amostra, aguardou-se pelo menos 1 min até o início da coleta de amostra, tempo suficiente para passagem de um volume de ar oriundo das bolhas pelo menos 2 vezes superior ao volume do headspace do funil ( 3,0 L). Durante as trocas de ponto de coleta dentro do tanque de aeração, moveu-se lateralmente o funil sem removê-lo do esgoto, evitando-se, dessa forma, a entrada de ar atmosférico no headspace do funil. Com base no volume total interno do tubo plástico $(\sim 40 \mathrm{~mL})$, removeu-se e desprezou-se 3 amostras de ar do interior do funil, totalizando assim $\sim 60 \mathrm{~mL}$, e aproveitou-se a quarta. Este procedimento foi adotado cada vez que se movia o funil de um local para outro tanto no tanque de aeração quanto no digestor de lodo.

\section{Balanço de massa}

Para determinação das concentrações de $\mathrm{N}_{2} \mathrm{O}$ no meio líquido (e.g., esgoto bruto, lodo e efluente) adotou-se a técnica do equilíbrio em headspace da seringa, a mesma descrita por Guimarães e de Mello ${ }^{11}$ para água do mar e semelhante à utilizada por Czepiel et al ${ }^{6}$ para extração de $\mathrm{N}_{2} \mathrm{O}$ do esgoto em ETE. Para isso, coletou-se $30 \mathrm{~mL}$ de amostra de líquido em seringa de $60 \mathrm{~mL}$ evitando-se a presença de bolhas de ar na amostra. Logo em seguida, a seringa foi preenchida com igual volume de ar atmosférico. Imediatamente após a amostragem a seringa foi agitada manualmente por 200 vezes e, em seguida, $\mathrm{o}$ ar contido no headspace da seringa foi cuidadosamente transferido para uma outra seringa seca, interligadas por torneiras de três vias.

Para o cálculo da concentração de $\mathrm{N}_{2} \mathrm{O}$ no esgoto, em nmol L-1, utilizou-se a Equação 4: ${ }^{11}$

$c_{\text {líquido }}=\left(K_{0} \times c_{\mathrm{hs}(\mathrm{f})}\right)+\left[(P / R T) \times\left(c_{\mathrm{hs}(\mathrm{f})}-c_{\mathrm{hs}(\mathrm{i})}\right)\right]$

onde $c_{\mathrm{hs}(\mathrm{f})}$ e $c_{\mathrm{hs}(\mathrm{i})}$ são, respectivamente, as concentrações de $\mathrm{N}_{2} \mathrm{O}(\mathrm{em}$ ppb) final (após agitação) e inicial (concentração de $\mathrm{N}_{2} \mathrm{O}$ no ar ambiente) no headspace da seringa, $K_{0}$ é o coeficiente de solubilidade do $\mathrm{N}_{2} \mathrm{O},{ }^{12} \mathrm{P}$ a pressão atmosférica, $R$ a constante universal dos gases e $T$ a temperatura do líquido na condição de equilíbrio (adotou-se a temperatura ambiente).

\section{Análises químicas}

$\mathrm{O} \mathrm{N}_{2} \mathrm{O}$, em amostras de ar (atmosférico, do interior da câmara e do funil) e do headspace resultante das extrações de amostras líquidas, foi analisado por cromatografia a gás num equipamento Shimadzu modelo GC-17A com detector de captura de elétrons $\left({ }^{63} \mathrm{Ni}\right)$. As especificidades dessa determinação encontram-se detalhadamente descritas em Guimarães e de Mello. ${ }^{9}$ As análises de $\mathrm{N}_{2} \mathrm{O}$ foram efetuadas até no máximo às 23:00 h do mesmo dia das coletas. A precisão analítica do $\mathrm{N}_{2} \mathrm{O}$ é de $\pm 1 \%$, valor que representa o coeficiente de variação das áreas dos picos de 5 réplicas do padrão inferior utilizado que foi de $356 \mathrm{ppb}$. Portanto, considerando-se uma variação de $\pm 1,8 \mathrm{ppb}$ em $20 \mathrm{~min}$, que foi o tempo de amostragem para determinação do fluxo, obtém-se, para $T=25^{\circ} \mathrm{C}$ e $P=1 \mathrm{~atm}$, um limite de quantificação \pm $1,4 \mu \mathrm{g} \mathrm{N}_{2} \mathrm{O} \mathrm{m}^{-2} \mathrm{~h}^{-1}$. 


\section{RESULTADOS E DISCUSSÃO}

\section{Elevatória de esgoto bruto - desarenador}

Após a passagem pela grade para a retirada de material grosseiro, o esgoto bruto escoa para a elevatória, contendo apenas o líquido e as partículas menores. Desse ponto é transferido, por bombeamento, para o desarenador, onde por sedimentação são removidos grãos de areia e materiais de menor tamanho. A Tabela 1 apresenta os resultados das concentrações de $\mathrm{N}_{2} \mathrm{O}$ no esgoto bruto na entrada da ETE e na saída do desarenador (entrada no tanque de aeração). Nas quatro ocasiões em que foram efetuadas as medidas, as concentrações médias no esgoto bruto foram sempre superiores em relação à saída do desarenador, o que sugere perda de $\mathrm{N}_{2} \mathrm{O}$ do esgoto para a atmosfera ao longo do percurso.

Tabela 1. Concentrações de $\mathrm{N}_{2} \mathrm{O}\left(\mathrm{nmol} \mathrm{L}^{-1}\right)$ na entrada de esgoto bruto da ETE e saída do desarenador (entrada no tanque de aeração)

\begin{tabular}{lcccccccc}
\hline \multirow{2}{*}{ Data } & \multicolumn{3}{c}{ Entrada da ETE } & \multicolumn{4}{c}{ Saída do desarenador } \\
& MA & Mín & Máx & $\mathrm{n}$ & MA & Mín & Máx & $\mathrm{n}$ \\
\hline $18 / 02 / 2008$ & 153 & 149 & 156 & 2 & 122 & 117 & 127 & 2 \\
$21 / 02 / 2008$ & 87,7 & 80,6 & 93,0 & 3 & 69,9 & 68,8 & 71,0 & 2 \\
$29 / 02 / 2008$ & 92,4 & 83,6 & 96,5 & 3 & 88,4 & 71,9 & 104 & 7 \\
$13 / 10 / 2008$ & 202 & 195,8 & 206,8 & 5 & 136 & 126 & 143 & 4 \\
\hline
\end{tabular}

MA = Média aritmética; Mín = Mínimo; Máx = Máximo; $\mathrm{n}$ = Número de determinações.

Com base em 8 dias de medidas de vazão de entrada de esgoto bruto na ETE, realizadas no período de março a outubro de 2008 das $8: 30$ às 16:00 h em intervalos de tempo de 1:30 h, estimou-se uma vazão média de $41 \mathrm{~m}^{3} \mathrm{~h}^{-1}\left(9,8 \times 10^{2} \mathrm{~m}^{3} \mathrm{dia}^{-1}\right)$. Para isso considerou-se que as vazões do período da noite e da madrugada (quando não eram feitas medidas) equivaleriam àquela primeira medida do início da manhã. Para efeito de cálculo de balanço, considera-se que a vazão de entrada do esgoto bruto é a mesma da saída do desarenador no tanque de aeração. Dessa forma, utilizando-se a vazão média e a diferença entre as concentrações médias de $\mathrm{N}_{2} \mathrm{O}$ na entrada do esgoto bruto (134 $\left.\mathrm{nmol} \mathrm{L}^{-1}\right)$ e a da saída do desarenador $\left(106 \mathrm{nmol} \mathrm{L}^{-1}\right)$, estima-se uma perda (emissão) de $\mathrm{N}_{2} \mathrm{O}$ do líquido (esgoto) para a atmosfera de $1,2 \mathrm{~g} \mathrm{~N}_{2} \mathrm{O}$ dia $^{-1}$. Extrapolando-se esse valor para a escala anual, obtém-se uma taxa de emissão de $4,4 \times 10^{2} \mathrm{~g} \mathrm{~N}_{2} \mathrm{O}$ ano $^{-1}$.

\section{Tanque de aeração}

Após o pré-tratamento, o esgoto bruto é conduzido, através do desarenador, ao tanque de aeração. As concentrações médias de $\mathrm{N}_{2} \mathrm{O}$ nas bolhas de ar que emergem da superfície do líquido na zona aeróbia apresentaram variações espaciais e temporais. Espacialmente, as concentrações de $\mathrm{N}_{2} \mathrm{O}$ nas bolhas de ar, em geral, aumentaram gradualmente da zona aeróbia para a zona anóxica. As medidas foram sempre realizadas sequencialmente das proximidades da passagem do tanque de aeração para o decantador secundário até as proximidades da chegada do esgoto bruto. A variação espacial foi mais significativa nos dias em que os valores de $\Delta\left[\mathrm{N}_{2} \mathrm{O}\right]$ (Equação 3 ) foram mais baixos (17/4/08 e 12/12/08). Nos demais dias, a razão entre o valor máximo e o mínimo foi inferior a 3 . A variação temporal foi bem expressiva. Nesse caso, os valores médios de $\Delta\left[\mathrm{N}_{2} \mathrm{O}\right]$ (Equação 3) ( \pm desvio padrão) variaram de $83 \pm 105$ ppb (mediana $=22 \mathrm{ppb})$, em 12/12/08, a $10.720 \pm 2.800 \mathrm{ppb}($ mediana $=11.150$ ppb), em 15/5/08. Essas altas variações nas concentrações de $\mathrm{N}_{2} \mathrm{O}$ foram aparentemente atribuídas a mudanças no controle da vazão de injeção de ar, uma prática algumas vezes necessária à otimização da eficiência dos processos microbiológicos atuantes no tanque de aeração. As observações mostram que as concentrações de $\mathrm{N}_{2} \mathrm{O}$ nas bolhas de ar emanadas eram maiores quanto maior era a aeração. Entretanto, a verificação da relação entre a concentração de $\mathrm{N}_{2} \mathrm{O}$ e o nível de aeração não foi possível visto que a vazão real de injeção de ar no tanque era desconhecida, pela ausência de um medidor de vazão na linha de injeção de ar.

Estudando os processos de produção de $\mathrm{NO}$ (óxido nítrico) e $\mathrm{N}_{2} \mathrm{O}$ em ETEs, Kampschreur et al..$^{4,13}$ concluíram que os três principais fatores de controle da produção desses gases nesses sistemas são: a concentração de oxigênio dissolvido, a concentração de nitrito $\left(\mathrm{NO}_{2}^{-}\right)$ e a taxa de aeração do esgoto. A concentração de oxigênio dissolvido é considerada um importante fator de controle na produção de $\mathrm{N}_{2} \mathrm{O}$ pela nitrificação. $\mathrm{O}$ rendimento de $\mathrm{N}_{2} \mathrm{O}$ nesse processo cresce com a diminuição dos níveis de oxigênio dissolvido. ${ }^{14} \mathrm{~A}$ desnitrificação é totalmente inibida por níveis elevados de oxigênio dissolvido. Bactérias oxidantes de amônia (ammonia-oxidizing bacteria) podem produzir $\mathrm{N}_{2} \mathrm{O}$ como sub-produto da oxidação da amônia a nitrito ou pela redução aeróbica de nitrito. ${ }^{15}$ Kampschreur et al. ${ }^{13}$ consideram que a desnitrificação conduzida por bactérias oxidantes de amônia seja o principal processo formador de $\mathrm{N}_{2} \mathrm{O}$ durante a aeração do esgoto em ETEs.

Com base nas Equações 2 e 3, estimaram-se as taxas de emissão de $\mathrm{N}_{2} \mathrm{O}$ no tanque de aeração (Tabela 2). Por não se dispor de meios de conhecer a vazão real de ar injetado no tanque de aeração, utilizou-se para isso a vazão de projeto $\left(460 \mathrm{~m}^{3} \mathrm{~h}^{-1}\right)$. As taxas de emissão médias de $\mathrm{N}_{2} \mathrm{O}$ variaram de 1,6 a $214 \mathrm{~g} \mathrm{~N}_{2} \mathrm{O}_{\text {dia }}{ }^{-1}$, variação temporal superior àquela verificada por Czepiel et al. ${ }^{6}$ no tanque de aeração de uma ETE municipal em Durham (New Hampshire, Estados Unidos), que foi de 17 a $259 \mathrm{~g} \mathrm{~N}_{2} \mathrm{O}$ dia $^{-1}$. No presente estudo, a taxa de emissão média foi de $80 \mathrm{~g} \mathrm{~N}_{2} \mathrm{O}$ dia $^{-1}$ (mediana $=51 \mathrm{~g} \mathrm{~N}_{2} \mathrm{O}$ dia $^{-1}$ ), equivalente a $2,9 \mathrm{x}$ $10^{4} \mathrm{~g} \mathrm{~N}_{2} \mathrm{O}$ ano $^{-1}$, valor semelhante àquele obtido por Czepiel et al. ${ }^{6}$ do tanque de aeração em Durham, 3,2 x $10^{4} \mathrm{~g} \mathrm{~N}_{2} \mathrm{O}$ ano $^{-1}$.

Tabela 2. Taxa de emissão de $\mathrm{N}_{2} \mathrm{O}\left(\mathrm{g} \mathrm{N}_{2} \mathrm{O}\right.$ dia $\left.^{-1}\right)$ do tanque de aeração (reator biológico)

\begin{tabular}{lcccc}
\hline Data & MA & Mín & Máx & $\mathrm{n}$ \\
$17 / 04 / 2008$ & 1,7 & 0,2 & 7,8 & 11 \\
$15 / 05 / 2008$ & 214 & 110 & 373 & 7 \\
$19 / 06 / 2008$ & 51 & 34 & 72 & 14 \\
$22 / 09 / 2008$ & 133 & 109 & 168 & 8 \\
$12 / 12 / 2008$ & 1,6 & $<0,1$ & 7,1 & 20 \\
\hline
\end{tabular}

MA = Média aritmética; Mín = Mínimo; Máx = Máximo; $\mathrm{n}=$ Número de determinações.

\section{Decantador secundário}

Do tanque de aeração, o esgoto tratado é transferido para o decantador secundário, que tem como função separar por sedimentação o lodo biológico, formado pelo crescimento bacteriano do esgoto tratado. Foram efetuadas um total de 9 medidas de fluxos de $\mathrm{N}_{2} \mathrm{O}$ na interface líquido (sobrenadante)-ar pelo método da câmara estática, realizadas em quatro ocasiões distintas. Individualmente, os fluxos variaram de $-0,6$ a $30 \mu \mathrm{g} \mathrm{N}_{2} \mathrm{O} \mathrm{m}^{-2} \mathrm{~h}^{-1}$, apresentando como média ( \pm desvio padrão) e mediana os valores $13,5 \pm 10,2$ e 15,7 $\mu \mathrm{g} \mathrm{N}_{2} \mathrm{O} \mathrm{m}^{-2} \mathrm{~h}^{-1}$, respectivamente $\mathrm{O}$ único valor negativo de fluxo encontra-se muito próximo ao limite de quantificação que foi de $\pm 1,4 \mu \mathrm{g} \mathrm{N}_{2} \mathrm{O} \mathrm{m}{ }^{-2} \mathrm{~h}^{-1}$. A Tabela 3 apresenta as médias das taxas de emissão de $\mathrm{N}_{2} \mathrm{O}$, nos dias de realização das medidas de fluxo, calculadas com base nos fluxos e na área superficial do decantador secundário $\left(60 \mathrm{~m}^{2}\right)$. Os resultados mostram taxas de emissão médias bastante baixas, na faixa de 0,008 a 0,043 $\mathrm{g} \mathrm{N}_{2} \mathrm{O}$ dia $^{-1}$, quando 
comparadas às do tanque de aeração. A taxa de emissão média de $\mathrm{N}_{2} \mathrm{O}$ do decantador secundário é de $0,022 \mathrm{~g} \mathrm{~N}_{2} \mathrm{O}$ dia $^{-1}$ ou 7,8 $\mathrm{g} \mathrm{N}_{2} \mathrm{O}$ $\mathrm{ano}^{-1}$, quatro ordens de grandeza inferior à taxa de emissão obtida para o tanque de aeração.

Tabela 3. Taxa de emissão de $\mathrm{N}_{2} \mathrm{O}\left(\mathrm{g} \mathrm{N}_{2} \mathrm{O}\right.$ dia $\left.{ }^{-1}\right)$ do decantador secundário

\begin{tabular}{lcl}
\hline Data & MA & $\mathrm{n}$ \\
\hline $23 / 10 / 2007$ & 0,013 & 2 \\
$18 / 02 / 2008$ & 0,008 & 2 \\
$21 / 02 / 2008$ & 0,043 & 1 \\
$16 / 12 / 2008$ & 0,022 & 4 \\
\hline
\end{tabular}

MA = Média aritmética; $\mathrm{n}=$ número de determinações.

\section{Recirculação do lodo}

O lodo acumulado no fundo do decantador secundário é, em grande parte, constituído por bactérias ativas do ponto de vista da capacidade de assimilar a matéria orgânica presente no esgoto, portanto, a importância da recirculação do lodo (retorno ao tanque de aeração) está no aumento do tempo médio de permanência dos micro-organismos no sistema. Os resultados compilados na Tabela 4 mostram significativa variabilidade temporal e tendências discordantes. As concentrações médias de $\mathrm{N}_{2} \mathrm{O}$ medidas no lodo recém-saído do fundo das câmaras do decantador secundário mostram uma variação superior a duas ordens de grandeza entre as diferentes ocasiões de coleta. Uma variação temporal superior a uma ordem de grandeza se verificou na entrada do lodo recirculado no tanque de aeração. Além disso, nas duas primeiras campanhas de coleta de amostras, as concentrações médias no lodo recémsaído do decantador foram inferiores às de sua entrada no tanque de aeração, ao passo que na última campanha se verificou o contrário. Isso pode ser explicado em termos de balanço na relação de produção de $\mathrm{N}_{2} \mathrm{O}$ no lodo e sua evasão para a atmosfera na linha de recirculação do lodo. Portanto, os resultados das duas primeiras campanhas mostram que houve acúmulo de $\mathrm{N}_{2} \mathrm{O}$ no lodo recirculado, ou seja, a produção de $\mathrm{N}_{2} \mathrm{O}$ superou seu escape para a atmosfera, enquanto que na última campanha o escape superou a produção.

Tabela 4. Concentração de $\mathrm{N}_{2} \mathrm{O}\left(\mathrm{nmol} \mathrm{L}^{-1}\right)$ no sistema de recirculação do lodo

\begin{tabular}{lllllllll}
\hline \multirow{2}{*}{ Data } & \multicolumn{3}{c}{ Saída do lodo do DS } & \multicolumn{4}{c}{ Retorno do lodo no TA } \\
& MA & Md & DP & n & MA & Md & DP & n \\
\hline $29 / 02 / 2008$ & 32,5 & 29,3 & 7,8 & 9 & 42,5 & 41,9 & 4,2 & 5 \\
$06 / 03 / 2008$ & 5,3 & 5,2 & 1,0 & 9 & 23,1 & 9,0 & 20,5 & 5 \\
$24 / 10 / 2008$ & 1046 & 1032 & 55,0 & 5 & 785 & 796 & 68,0 & 5 \\
\hline
\end{tabular}

DS = Decantador secundário; $\mathrm{TA}=$ Tanque de aeração; $\mathrm{MA}=$ Média aritmética; $\mathrm{Md}=$ Mediana; $\mathrm{DP}=$ Desvio Padrão; $\mathrm{n}$ = Número de determinações.

O processo de recirculação do lodo é intermitente, com intervalos de acionamento da bomba da elevatória do lodo de $15 \mathrm{~min}$. Nesse caso, a vazão e o período de bombeamento médio são $16 \mathrm{~L}$ $\mathrm{s}^{-1}$ e 4,7 min, resultando numa vazão equivalente a $18 \mathrm{~m}^{3} \mathrm{~h}^{-1}$. Com base nessa vazão e na diferença de concentração de $\mathrm{N}_{2} \mathrm{O}$ entre a saída do lodo do decantador secundário e seu retorno ao tanque de aeração na última campanha, obtém-se uma taxa de emissão da ordem de 4,7 $\mathrm{g} \mathrm{N}_{2} \mathrm{O}$ dia $^{-1}$ ou $1,7 \times 10^{3} \mathrm{~g} \mathrm{~N}_{2} \mathrm{O}$ ano $^{-1}$. Recomenda-se cautela com esse resultado uma vez que foi calculado com base em uma única campanha que não teve o mesmo comportamento em relação às outras duas realizadas. A taxa de emissão de $\mathrm{N}_{2} \mathrm{O}$ resultante da recirculação do lodo é pouco mais que uma ordem de grandeza inferior àquela obtida para o tanque de aeração.

\section{Digestor de lodo}

Quando o lodo do tanque de aeração se encontra estabilizado, ele é transferido para o digestor de lodo onde é aerado antes de ser descartado para os leitos de secagem. As concentrações médias de $\Delta\left[\mathrm{N}_{2} \mathrm{O}\right]$ nas bolhas de ar que emergem da superfície do líquido no digestor de lodo variaram pouco entre as duas ocasiões em que foram realizadas as medições, ou seja, $333 \pm 232 \mathrm{ppb}$ (mediana $=320 \mathrm{ppb}$ ), em 19/6/08, e $136 \pm 49$ ppb (mediana = 116 ppb), em 13/10/08. Tal qual para o tanque de aeração, utilizaram-se as Equações 2 e 3 para o cálculo das taxas de emissão de $\mathrm{N}_{2} \mathrm{O}$ no digestor de lodo (Tabela 5). Nesse caso, utilizou-se a vazão de aeração do digestor de lodo de projeto, calculada em $240 \mathrm{~m}^{3} \mathrm{~h}^{-1}$. A taxa de emissão média de $\mathrm{N}_{2} \mathrm{O}$ é de $2,4 \mathrm{~g} \mathrm{~N}_{2} \mathrm{O}$ dia $^{-1}$, que na escala anual representa $8,8 \times 10^{2} \mathrm{~g} \mathrm{~N}_{2} \mathrm{O}$ $\mathrm{ano}^{-1}$, valor duas vezes inferior àquele obtido por Czepiel et al. ${ }^{6}$ para o tanque de estocagem de lodo (sludge storage tank), que foi 1,7 x $10^{3} \mathrm{~g} \mathrm{~N}_{2} \mathrm{O}$ ano $^{-1}$.

Tabela 5. Taxa de emissão de $\mathrm{N}_{2} \mathrm{O}\left(\mathrm{g} \mathrm{N}_{2} \mathrm{O}\right.$ dia $\left.^{-1}\right)$ do digestor de lodo

\begin{tabular}{lllll}
\hline Data & MA & Md & DP & n \\
\hline $19 / 06 / 2008$ & 3,4 & 3,3 & 2,4 & 9 \\
$13 / 10 / 2008$ & 1,4 & 1,2 & 0,5 & 10 \\
\hline
\end{tabular}

$\overline{\mathrm{MA}}=$ Média aritmética; $\mathrm{Md}=$ Mediana; $\mathrm{DP}=$ Desvio padrão; $\mathrm{n}=$ Número de determinações.

\section{Efluente}

No final do processo, o sobrenadante do decantador secundário é transferido para o corpo receptor, constituindo o efluente da ETE. A Tabela 6 apresenta os resultados das concentrações de $\mathrm{N}_{2} \mathrm{O}$ no líquido na saída do decantador secundário e na saída do efluente no corpo receptor. As concentrações na saída do decantador secundário foram sempre superiores às da saída do efluente da ETE (lançamento no corpo receptor), cujas médias foram respectivamente 38 e $21 \mathrm{nmol}$ $\mathrm{L}^{-1}$, o que sugere perda de $\mathrm{N}_{2} \mathrm{O}$ para a atmosfera ao longo do percurso.

Tabela 6. Concentração de $\mathrm{N}_{2} \mathrm{O}\left(\mathrm{nmol} \mathrm{L}^{-1}\right)$ no efluente de saída do decantador secundário e da estação de tratamento de esgoto (ETE)

\begin{tabular}{lllllllll}
\hline \multirow{2}{*}{ Data } & \multicolumn{9}{c}{ Saída do efluente do TD } & \multicolumn{7}{c}{ Saída da ETE } \\
& MA & Md & DP & n & MA & Md & DP & n \\
\hline $21 / 02 / 2008$ & 9,2 & 10,3 & 3,2 & 3 & 7,9 & 7,7 & 0,5 & 3 \\
$29 / 02 / 2008$ & 44,3 & 41,4 & 8,0 & 3 & 28,7 & - & - & 2 \\
$13 / 10 / 2008$ & 60,9 & 61,5 & 2,2 & 5 & 25,7 & 27,9 & 5,2 & 5 \\
\hline
\end{tabular}

$\mathrm{TD}=$ Tanque de decantação; $\mathrm{MA}=$ Média aritmética; $\mathrm{Md}=$ Mediana; $\mathrm{DP}=$ Desvio Padrão; $\mathrm{n}=$ Número de determinações.

Com base em medidas de vazão na saída do efluente da ETE, realizadas entre março e outubro de 2008, estimou-se uma vazão média de $21 \mathrm{~m}^{3} \mathrm{~h}^{-1}$. Para efeito de cálculo de balanço, considera-se que as vazões nesses locais da ETE são as mesmas. Com base nos valores de vazão e da diferença entre as concentrações médias de $\mathrm{N}_{2} \mathrm{O}$ nas saídas do decantador secundário e do efluente no corpo receptor, estima-se, para esse trecho, uma taxa de emissão de $\mathrm{N}_{2} \mathrm{O}$ do líquido (esgoto tratado) para a atmosfera de $0,4 \mathrm{~g} \mathrm{~N}_{2} \mathrm{O}$ dia $^{-1}$, equivalente a $1,5 \times 10^{2} \mathrm{~g} \mathrm{~N}_{2} \mathrm{O} \mathrm{ano}^{-1}$.

De acordo com a Tabela 6, a concentração de $\mathrm{N}_{2} \mathrm{O}$ no efluente ao ser lançado no corpo receptor (i.e., saída da ETE) é superior à concentração de $\mathrm{N}_{2} \mathrm{O}$ na água em equilíbrio com a atmosfera, que é $7,7 \mathrm{nmol} \mathrm{L}^{-1}$ (concentração de saturação em água doce a $\mathrm{T}=25^{\circ} \mathrm{C}$ ). Assumindo-se que toda a parcela supersaturada de $\mathrm{N}_{2} \mathrm{O}$ possa, por difusão, ser totalmente transferida para a atmosfera, isso representa 
uma taxa de emissão adicional de $0,5 \mathrm{~g} \mathrm{~N}_{2} \mathrm{O} \mathrm{dia}{ }^{-1}$, ou 1,7 x $10^{2} \mathrm{~g} \mathrm{~N}_{2} \mathrm{O}$ $\mathrm{ano}^{-1}$, após a descarga do efluente no corpo receptor. $\mathrm{O}$ que totaliza uma taxa de emissão de $3,2 \times 10^{2} \mathrm{~g} \mathrm{~N}_{2} \mathrm{O}$ ano $^{-1}$ para todo o trecho a partir da saída do sobrenadante do tanque de decantação. Nesse cálculo não se considera a geração de $\mathrm{N}_{2} \mathrm{O}$ no corpo receptor resultante de atividades microbiológicas (nitrificação e/ou desnitrificação) atuantes sobre o nitrogênio amoniacal $\left(\mathrm{NH}_{4}^{+}+\mathrm{NH}_{3}\right)$, nitrito e nitrato associados ao efluente.

\section{CONCLUSÕES}

A taxa de emissão total de $\mathrm{N}_{2} \mathrm{O}$ da estação de tratamento de esgoto (ETE) estudada foi de $3,2 \times 10^{4} \mathrm{~g} \mathrm{~N}_{2} \mathrm{O} \mathrm{ano}^{-1}$. De todas as unidades que compõem a ETE, só não se efetuou medidas de fluxos de $\mathrm{N}_{2} \mathrm{O}$ sobre o lodo, oriundo do digestor de lodo, após seu descarte nos leitos de secagem. A contribuição relativa, no que tange à emissão de $\mathrm{N}_{2} \mathrm{O}$, das diversas unidades da ETE decresce na seguinte ordem: tanque de aeração $(90 \%)$, recirculação do lodo (5\%), digestor de lodo (3\%), entrada do esgoto bruto-desarenador (1\%), efluente $(1 \%)$ e decantador secundário $(<<1 \%)$. Czepiel et al. ${ }^{6}$ verificaram que $91 \%$ das emissões de $\mathrm{N}_{2} \mathrm{O}$ de uma ETE em Durham (EUA) se originavam do tanque de aeração. As variações temporais associadas ao desprendimento de $\mathrm{N}_{2} \mathrm{O}$ do tanque de aeração e na recirculação do lodo da ETE estudada são, entretanto, significativamente altas. No tanque de aeração, a principal unidade-fonte de $\mathrm{N}_{2} \mathrm{O}$, a emissão desse gás está, aparentemente, associada ao grau de aeração do esgoto.

Considerando-se que a ETE estudada atende a cerca de 2.500 usuários e possui uma vazão média de entrada de esgoto de $40 \mathrm{~m}^{3}$ $\mathrm{h}^{-1}$, cuja concentração média de nitrogênio $(\mathrm{N})$ total é $42 \mathrm{mg} \mathrm{N}$ $\mathrm{L}^{-1}$, os fatores de emissão (FEs) de $\mathrm{N}_{2} \mathrm{O}$ per capita, por vazão de esgoto tratado e pela carga de entrada de nitrogênio total (associada ao esgoto) na ETE são: $13 \mathrm{~g} \mathrm{~N}_{2} \mathrm{O}$ pessoa $^{-1} \mathrm{ano}^{-1}, 9,0$ x $10^{-5} \mathrm{~g} \mathrm{~N}_{2} \mathrm{O}$ $\mathrm{L}_{\text {esgoto }}{ }^{-1}$ e $0,14 \%$ da carga de $\mathrm{N}$ (\% of $\mathrm{N}$-load). Esse último representa a razão entre a carga de $\mathrm{N}_{2} \mathrm{O}$ (em massa de $\mathrm{N}$ ) emitida da ETE e a carga de entrada de nitrogênio total na ETE. Esses FEs são superiores àqueles obtidos por Czepiel et al., ${ }^{6} 3,2 \mathrm{~g} \mathrm{~N}_{2} \mathrm{O}$ pessoa $^{-1} \mathrm{ano}^{-1}$ e $3,2 \times 10^{-5} \mathrm{~g} \mathrm{~N}_{2} \mathrm{O} \mathrm{L}_{\text {esgoto }}{ }^{-1}$, numa ETE destinada ao tratamento de esgoto exclusivamente doméstico. Em Chiba, Japão, Kimochi et $a l .{ }^{16}$ encontraram FEs por população servida e por carga de entrada de nitrogênio total na ETE nas faixas de 0,43 a 1,9 $\mathrm{g} \mathrm{N}_{2} \mathrm{O}$ pessoa $^{-1}$ $\mathrm{ano}^{-1}$ e de 0,01 a $0,08 \%$. Por carga de entrada de nitrogênio total na ETE, Kampschreur et al. ${ }^{13}$ encontraram, em uma ETE em Rotterdam (Holanda), um FE de 2,3\%.

As Diretrizes de 2006 do IPCC para Inventários de Gases do Efeito Estufa ${ }^{6}$ sugerem como fator de emissão de $\mathrm{N}_{2} \mathrm{O}$ para estimativas de $\mathrm{N}_{2} \mathrm{O}$ de ETEs o valor 3,2 (faixa: 2-8) $\mathrm{g} \mathrm{N}_{2} \mathrm{O}$ pessoa $^{-1} \mathrm{ano}^{-1}$, decorrente do trabalho de Czepiel et al.. ${ }^{6}$ Este fator é recomendado para países que possuam sistemas centralizados de tratamento de esgoto com avançado controle dos processos de nitrificação e desnitrificação.
Os resultados do presente estudo são preliminares, uma vez que não foram obtidos de uma estação destinada ao tratamento de esgoto de origem exclusivamente doméstica, e mostram uma variabilidade temporal superior àquela apresentada por Czepiel et al. ${ }^{6}$ no que tange às emissões de $\mathrm{N}_{2} \mathrm{O}$ do tanque de aeração, a principal unidade-fonte de $\mathrm{N}_{2} \mathrm{O}$. Entretanto, sugerem que as emissões de $\mathrm{N}_{2} \mathrm{O}$ de uma ETE de lodos ativados por aeração prolongada numa região de clima tropical possam ser superiores às de regiões de clima temperado.

\section{AGRADECIMENTOS}

Ao Conselho Nacional de Desenvolvimento Científico e Técnológico (CNPq Universal, Proc. 477073/2007-7) e ao Programa Estratégico de Pesquisa em Saúde (Fiocruz/CNPq, Proc. 0477) pelos auxílios financeiros concedidos, e ao CNPq (PIBIC/Fiocruz) pela bolsa de iniciação científica concedida a A. C. Brotto.

\section{REFERÊNCIAS}

1. http://www.ipcc.ch/pdf/assessment-report/ar4/wg1/ar4-wg1-chapter2. pdf, acessada em Agosto 2009.

2. McElroy, M. B.; The Atmospheric Environment Effects of Human Activities, Princeton University Press: Princeton, 2002.

3. Olivier, J. G. J.; Bouwman, A. F.; van der Hoek, K. W.; Berdowski, J. J. M.; Environ. Pollut. 1998, 102, 135.

4. Kampschreur, M. J.; Temmink, H.; Kleerebezem, R.; Jettem, M. S. M.; van Loosdrecht, M. C. M.; Water Res. 2009, 43, 4093.

5. http://www.ipcc-nggip.iges.or.jp/public/2006gl/pdf/5_Volume5/V5_6_ Ch6_Wastewater.pdf, acessada em Agosto 2009.

6. Czepiel, P.; Crill, P.; Harriss, R.; Environ. Sci. Technol. 1995, 29, 2352.

7. von Sperling, M.; Princípios do Tratamento Biológico de Águas Residuárias, Departamento de Engenharia Sanitária, UFMG: Belo Horizonte, 1997, vol. 4.

8. Goreau, T. J.; de Mello, W. Z.; Ambio 1988, 17, 275.

9. Goreau, T. J.; de Mello, W. Z. Em The Everglades Florida Bay and Coral Reefs of the Florida Keys - An Ecosystem Sourcebook; Porter, J. W.; Porter, K. G., eds.; CRC Press: Boca Raton, 2002, cap. 10.

10. de Mello, W. Z.; Goreau, T. J.; Geochim. Brasil. 1998, 12, 17.

11. Guimarães, G. P.; de Mello, W. Z.; Quim. Nova 2008, 31, 1613.

12. Weiss, R. F.; Price, B. A.; Mar. Chem. 1980, 8, 347.

13. Kampschreur, M. J.; van der Star, W. R. L.; Wielders, H. A.; Mulder, J. W.; Jetten, M. S. M.; van Loosdrecht, M. C. M.; Water Res. 2008, 42, 812.

14. Goreau, T. J.; Kaplan, W. A.; Wofsy, S. C.; McElroy, M. B.; Valois, F. W.; Watson, S. W.; Appl. Environ. Microbiol. 1980, 40, 526.

15. Colliver, B. B.; Stephenson, T.; Biotechnol. Adv. 2000, 18, 219.

16. Kimochi, Y.; Inamori, Y.; Mizuochi, M.; Xu, K.-Q.; Matsumura, M.; J. Ferment. Bioeng. 1998, 86, 202. 